\title{
Chapter 22 \\ Make No Little Plans: The Lucian \\ Leape Institute
}

Despite encouraging progress in the early years of the patient safety movement, it soon became evident that there were deeper issues that needed to be addressed. We realized that we were not going to make health care safe by making process changes one by one, even powerful changes such as eliminating CLABSI or implementing the surgical checklist.

We needed to fundamentally reimagine the way we think about delivery of health care. Health care needed not just to be improved but to be transformed. A sustainable strategy-probably several strategies - was needed to enable us to deal with the fundamental systemic and behavioral issues that drive unsafe behavior.

Fortunately, as noted in Chap. 5, in 2007 the National Patient Safety Foundation created a mechanism to do that, the Lucian Leape Institute, a "think tank" of experts whose leadership roles had given them experience and insights that would enable them to identify the issues and make authoritative recommendations for changes.

The charge to the Institute was to "define strategic paths and calls to action for the field of patient safety and provide vision and context for the many efforts underway within the health care system. Through its Roundtables, it will issue reports that will guide the work of the field and challenge the system to address the issues critical to making the system safer." 
I chaired the Institute. The other initial members were:

- Don Berwick, founder and CEO of the Institute for Healthcare Improvement, who brought quality improvement to health care

- Carolyn Clancy, Director, Agency for Healthcare Research and Quality, who spearheaded its early work on safety

- Jim Conway, Senior VP, Institute for Healthcare Improvement and previous COO of Dana-Farber Cancer Institute, who led its reorganization for safety

- David Lawrence, CEO of Kaiser Foundation Health Plan, former Executive Session member, who brought patient safety to Kaiser-Permanente

- Julianne Morath, Chief Quality and Safety Officer, Vanderbilt University Medical Center, who led Allina Health's entry into patient safety

- Dennis O'Leary, President of the Joint Commission, also a former Executive Session member, who focused the Commission on patient safety

- Paul Gluck, immediate past chair of NPSF Board of Directors

- Diane Pinakiewicz, President of NPSF

At the first meeting of the Lucian Leape Institute, we had a lively discussion about our purpose and how to most effectively go about strategic planning. After surfacing dozens of ideas, we decided to focus our efforts on core concepts that we believed were foundational to achieving meaningful improvement in patient safety.

They were obviously not the only thing needed, but we believed they were essential. Without embracing these concepts, health-care
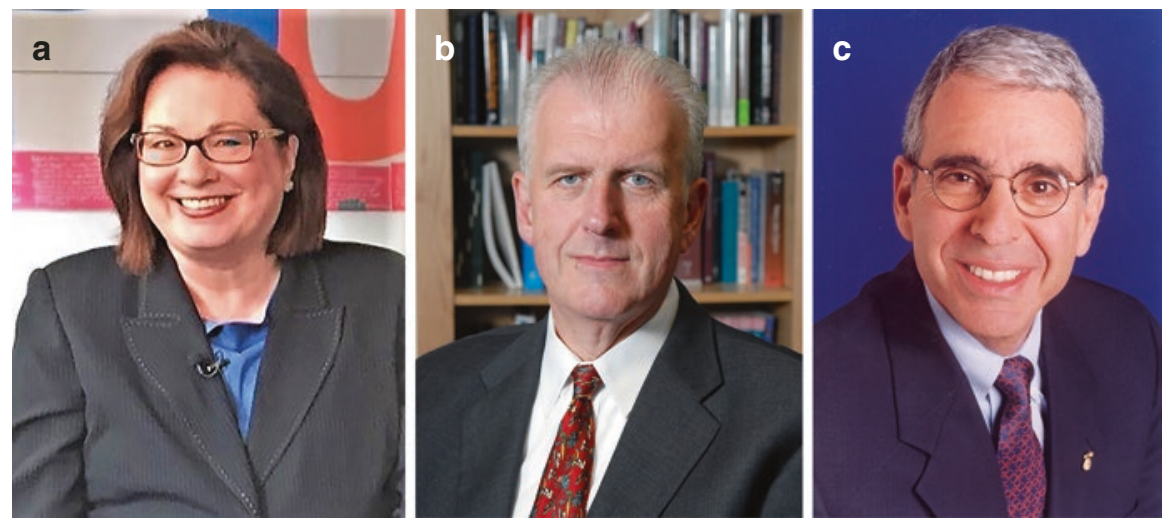

(a) Julie Morath, (b) Jim Conway, and (c) Paul Gluck. (All rights reserved) 
organizations could not mobilize the resources and motivate their workforce to achieve safe care. We identified five concepts: Reforming Medical Education, Integrating Care, Finding Joy and Meaning in Work, Patient Engagement, and Transparency. We called them Transforming Concepts.

Each concept requires a change of consciousness to move thinking beyond traditional boundaries, and each implies profound behavioral changes. We wrote a paper, Transforming health care: a safety imperative, that explained the transforming concepts, summarized the importance of each, and defined the issues to be resolved [1]. Then we set to work.

Over the next several years, LLI convened a roundtable of national experts and stakeholders, including patient advocates, for each of the five concepts to explore the critical issues, understand them better, and make recommendations for transformative change. To stimulate buy-in and ownership, we made a special effort to include on each panel leaders of organizations for which the issue was especially relevant and who could implement the recommendations. LLI members chaired the roundtables.

The typical roundtable had 25-30 participants and met twice in two-day sessions. We had no trouble recruiting members for each topic; the relevant thought leaders shared our interest and were eager to participate. Prior to convening, we provided participants with a comprehensive literature review on the topic. The discussions were spirited and wide-ranging and concluded with recommendations for health-care organizations and their leaders.

Following each roundtable, the leaders wrote a white paper that combined facts and insights from the literature with the results of the panel discussions to provide a comprehensive account of the topic with specific recommendations for action by health-care providers, leaders, and policy makers. These white papers are available, free of charge from IHI at IHI.org.

The five white papers are summarized below, including for each also a review of progress made since the paper was published and a discussion of remaining challenges. These are verbatim combinations of text taken from two summaries later published by LLI: Transforming Health Care: A Compendium of Reports from the National Patient Safety Foundation's Lucian Leape Institute, IHI, 2016 [2], and Transforming concepts in patient safety: a progress report. BMJ Quality \& Safety, 2018 [3]. 


\section{Unmet Needs [4]}

\section{Teaching Physicians to Provide Safe Patient Care}

\section{Workshop Leaders: Dennis O'Leary and Lucian Leape}

Health-care delivery continues to be unsafe despite major patient safety improvement efforts over the past decade. The roundtable concluded that substantive improvements in patient safety will be difficult to achieve without major medical education reform at the medical school and residency training program levels. Medical schools must assure that future physicians not only have the requisite knowledge, skills, behaviors, and attitudes to practice competently but also are prepared to play active roles in identifying and resolving patient safety problems. These competencies should become fully developed during the residency training period.

Medical schools today focus principally on providing students with the knowledge and skills they need for the technical practice of medicine but often pay inadequate attention to the shaping of student skills, attitudes, and behaviors that will permit them to function safely and as architects of patient safety improvement in the future. Specifically, medical schools are not doing an adequate job of facilitating student understanding of basic knowledge and the development of skills required for the provision of safe patient care, to wit: systems thinking, problem analysis, application of human factors science, communication skills, patient-centered care, teaming concepts and skills, and dealing with feelings of doubt, fear, and uncertainty with respect to medical errors.

In addition, medical students all too often suffer demeaning experiences at the hands of faculty and residents, a phenomenon that appears to reflect serious shortcomings in the medical school and teaching hospital cultures. Behaviors like these that are disruptive to professional relationships have adverse effects upon students, residents, nurses, colleagues, and even patients. Students frequently tend to emulate these behaviors as they become residents and practicing clinicians, which perpetuates work environments and cultures that are antithetical to the delivery of safe, patient-centered care.

Summary of Recommendations (Table 22.1) 
Table 22.1 Key recommendations from Unmet Needs: Teaching Physicians to Provide Safe Patient Care

\begin{tabular}{|c|c|}
\hline $\begin{array}{l}\text { Target of } \\
\text { recommendation }\end{array}$ & Recommendation \\
\hline $\begin{array}{l}\text { Medical school } \\
\text { and hospital } \\
\text { leaders }\end{array}$ & $\begin{array}{l}\text { Place the highest priority on creating a learning culture that } \\
\text { emphasizes patient safety, professionalism, transparency, } \\
\text { and valuing the individual learner } \\
\text { Eliminate hierarchical and authority gradients } \\
\text { Emphasize that professionalism includes demonstrating } \\
\text { mutual respect and non-tolerance of abusive or demeaning } \\
\text { behavior } \\
\text { Declare and enforce a zero-tolerance policy for confirmed } \\
\text { egregious disrespectful behavior by faculty, staff, or } \\
\text { residents } \\
\text { Promote the development of interpersonal skills, } \\
\text { leadership, teamwork, and collaboration among faculty and } \\
\text { staff } \\
\text { Provide incentives and resources to enhance faculty } \\
\text { capabilities to teach and practice patient safety and to be } \\
\text { effective role models } \\
\text { The selection process for admission to medical schools } \\
\text { should emphasize attributes that reflect professionalism and } \\
\text { orientation to patient safety, such as compassion, empathy, } \\
\text { and collaboration }\end{array}$ \\
\hline Medical schools & $\begin{array}{l}\text { Treat patient safety as a science that encompasses human } \\
\text { factors, systems theory, and open communication } \\
\text { Emphasize the shaping of desired skills, attitudes, and } \\
\text { behaviors as set forth in the core competencies defined by } \\
\text { the IOM, the American Board of Medical Specialties, and } \\
\text { the Accreditation Council for Graduate Medical Education } \\
\text { The educational experience should be coherent, continuing, } \\
\text { and flexible throughout undergraduate medical education, } \\
\text { residency and fellowship training, and lifelong continuing } \\
\text { education }\end{array}$ \\
\hline $\begin{array}{l}\text { Accrediting } \\
\text { bodies }\end{array}$ & $\begin{array}{l}\text { Amend medical school accreditation requirements and } \\
\text { residency program requirements to include expectations for } \\
\text { the creation of learning cultures and the development of } \\
\text { patient safety-related behavioral traits. } \\
\text { Survey medical schools to evaluate education priorities for } \\
\text { patient safety and the creation of school and hospital } \\
\text { cultures that support patient safety }\end{array}$ \\
\hline
\end{tabular}




\section{Progress}

In recent years, medical school curricula have increasingly included patient safety and safety science, and these concepts have also become more common in education for other clinicians and frontline staff. For example, the American Medical Association's Accelerating Change in Medical Education Consortium brought medical schools together to innovate, develop curricula, and share best practices, including those addressing quality and safety.

The Accreditation Council for Graduate Medical Education Clinical Learning Environment Review (ACGME CLER) program requires medical resident participation in quality and safety learning. Recently, the Association of American Medical Colleges (AAMC) initiated a program to create a shared understanding of Quality Improvement and Patient Safety (QIPS) competencies across the full continuum from medical school to continuing practice.

Other clinical disciplines, particularly nursing, have often pioneered educational pathways, and a concerted effort is underway to emphasize the importance of interprofessional teams. The Quality and Safety Education for Nurses (QSEN) program has focused on enhancing education around safety science in nursing schools for more than a decade. More recently, the National Collaborative for Improving the Clinical Learning Environment (NCICLE) highlighted the "patient safety gap" in the education and training of all clinicians and provided clear recommendations for improvement [3].

To assist health-care students and professionals in building core skills in improvement, safety, and leadership, the Institute for Healthcare Improvement (IHI) developed a web-based interactive educational program called the Open School. More than 650,000 learners have enrolled in the Open School since it opened its virtual doors in 2008.

To address the need for training in postgraduate medical education, in 2012 the NPSF created a course in patient safety and safety science that more than 7000 learners of diverse disciplines have utilized. Several universities have developed graduate education and fellowships in quality and safety, and clinicians, risk managers, pharmacists, executives, and others have pursued these as well as certificate programs and professional certification in patient safety. 


\section{Remaining Challenges}

Still, opportunity lies ahead for greater consistency in how health professionals learn about patient safety. A 2016 report from ACGME CLER reveals gaps in areas such as feedback on safety reporting and experiential learning, lack of awareness of the range of patient safety issues, and shortage of opportunities for interprofessional systembased improvement efforts. Contributing to this learning gap is a shortage of academic faculty with safety and quality improvement expertise.

Continuing education requirements for attending physicians are highly variable. While some medical specialties require continuing education in patient safety, the American Board of Internal Medicine recently removed it as a requirement from Maintenance of Certification. Health-care organizations would benefit from encouraging study of safety science by all team members, including board members, and operationalizing ways to achieve continuous learning as safety science expands.

As these and other activities gain momentum, the core agenda remains consistent, clear, and urgent: to mainstream the preparation of health professionals' awareness, skills, commitment, and practical training about the scientific pursuit of safer care. Embracing the science of safety in medical education is crucial to the future health and well-being of patients, families, and communities.

\section{Order from Chaos [5]}

\section{Accelerating Care Integration}

\section{Workshop Leaders: David Lawrence and Richard Bohmer}

Lack of care coordination and integration was identified as a major contributor to the frequency of avoidable errors in patient care in the Institute of Medicine (IOM) report To Err Is Human (1999). Care integration was presented as the cornerstone for achieving high quality in the subsequent IOM report Crossing the Quality Chasm (2001). The Agency for Healthcare Research and Quality (AHRQ) has 
included care integration and patient safety in its scope of work since early in this decade. Federal government administration arguments for the Patient Protection and Affordable Care Act of 2010 included numerous references to this issue.

Modern care delivery is extraordinarily complex. To protect the patient and avoid errors require a planned, coordinated, and fully integrated approach to care. In addition to the complexity inherent in modern treatment for patients with difficult and often multiple conditions, complexity is found throughout the care experience: in the number of physicians involved, the number of professionals and support personnel required, the multiple venues where care is provided, and the diverse requirements and expectations of patients. As a consequence, the risks of harm also rise unless careful attention is given to the way care is organized and delivered, that is, to the system of care delivery itself. The system must be designed to protect the patient while ensuring that he or she receives the full benefits of the remarkable advances that have occurred over the past century.

And here we arrive at care integration, the planned, thoughtful design of the care process for the benefit and protection of the patient. Unfortunately, physicians and leaders of delivery systems (with notable exceptions such as those at the Mayo Clinic, Geisinger Health System, and Kaiser-Permanente) have been unwilling or unable to embrace greater care integration. As described in Crossing the Quality Chasm, most patient care is fragmented and uncoordinated. Where integration has occurred, it is most often structural: assembling piece parts under a single governance umbrella while leaving the underlying care delivery processes largely untouched.

The care delivery system is struggling to escape the straitjacket of physician autonomy and economic independence, a payment system that reinforces fragmentation and independent decision-making, and a regulatory framework that places legal responsibility on the individual professional without corresponding accountability of the team or the system within which that professional works. The medical education system reinforces these expectations and does little to prepare new physicians for the team-based, interdependent work that is required to achieve high-quality and safe care.

Summary of Recommendations (Table 22.2) 
Table 22.2 Key recommendations from Order from Chaos: Accelerating Care Integration

\begin{tabular}{l|l}
\hline Target of recommendation & Recommendation \\
\hline $\begin{array}{l}\text { All stakeholders: federal } \\
\text { agencies, consumer groups }\end{array}$ & $\begin{array}{l}\text { Create mechanisms for developing a shared } \\
\text { understanding among public and private } \\
\text { stakeholders regarding the link between care } \\
\text { integration and patient safety } \\
\text { Utilize working groups and public forums, best } \\
\text { practices, and patient stories to be catalogued } \\
\text { and disseminated }\end{array}$ \\
\hline $\begin{array}{l}\text { Health-care leaders and } \\
\text { practitioners, public }\end{array}$ & $\begin{array}{l}\text { Patients and families must become active } \\
\text { participants in process improvement and design } \\
\text { and redesign efforts and review organizational } \\
\text { performance }\end{array}$ \\
\hline $\begin{array}{l}\text { Regulatory and accrediting } \\
\text { bodies }\end{array}$ & $\begin{array}{l}\text { Create methods of measuring care integration, } \\
\text { along with robust assessment and evaluation } \\
\text { metrics, and incorporate these measures into } \\
\text { public reporting systems }\end{array}$ \\
\hline $\begin{array}{l}\text { Medical schools, } \\
\text { professional societies, } \\
\text { nonprofits }\end{array}$ & $\begin{array}{l}\text { Provide education and training for executives, } \\
\text { boards, clinicians, and medical students that } \\
\text { focus on patient safety and care integration }\end{array}$ \\
\hline Researchers, industry & $\begin{array}{l}\text { Develop the technology and infrastructure to } \\
\text { allow for national spread of organizational and } \\
\text { operational expertise to support care integration }\end{array}$ \\
\hline
\end{tabular}

\section{Progress}

With an increased call for improved coordination of care and focus on patient safety across the care continuum, methods for improving handoffs and communication among teams, providers, and patients are gaining traction. Today the focus on population health and marketspecific shifts in payment models serve as incentives for greater care integration and coordination.

Progress has been made to develop systems and structures to encourage and incentivize care integration. Accountable care organizations (ACOs) have brought together groups of health providers to incentivize better quality care at a lower cost. Likewise, the development of the patient-centered medical home (PCMH) aims to reorganize and reinvigorate primary care, and early evidence shows promise in achieving lower costs, improved patient experience, and better care quality. 
Other encouraging examples of improved care integration include Project Re-Engineered Discharge (Project RED), the PCORI-funded Project ACHIEVE (Achieving Patient-Centered Care and Optimized Health In Care Transitions by Evaluating the Value of Evidence), and the Johns Hopkins School of Nursing-led Community Aging in Place: Advancing Better Living for Elders (CAPABLE). For example, Project RED developed strategies to improve the hospital discharge process to promote patient safety and has been proven to reduce rehospitalizations and yield high rates of patient satisfaction.

Finally, the increase in employed physicians and continued refinement of the electronic health record have accelerated care integration. Improving interoperability of health information technology has been a major initiative at the federal level to improve information flow across the entire care continuum.

\section{Remaining Challenges}

Despite incremental improvement, coordination and integration of care remain difficult, particularly for patients with multiple chronic conditions. Even with a national push toward more integrated care models (perhaps most focused on the development of ACOs), so far results toward safer, more coordinated care have been mixed. Furthermore, care integration issues are compounded for older adults. One study found that the average Medicare beneficiary spent about 17 days in contact with the health-care system through an average of 3.4 different clinicians. Only 55\% of these individuals coordinated their care principally with a single primary care physician.

Structural changes alone will not ensure optimal care integration. Strong clinician leadership and patient engagement will be required to further improve care coordination. Involving patients and families in the codesign of care, especially around coordination and care delivered in the home, will help identify unmet needs and educational deficits.

Care integration remains perhaps the most challenging of the transforming concepts because of the fragmentation of the US health-care system. When Americans are asked to reflect on the integration of care from their own experiences, some refer to the term "health-care system" as an oxymoron. 
Individuals responsible for coordinating care and helping patients navigate the care system include primary care physicians, specialists, nurses, pharmacists, social workers, and care managers, as well as health plan and delivery system personnel. As care becomes more complex and shared among more providers, it is essential to improve both processes (e.g., teamwork, communication, and patient engagement) and technologies (e.g., EHRs) for patients and providers.

\section{Through the Eyes of the Workforce [6]}

\section{Creating Joy, Meaning, and Safer Health Care}

\section{Workshop Leaders: Julie Morath and Paul O’Neill}

The health-care workforce is composed of well-intentioned, well-prepared people in a variety of roles and clinical disciplines who do their best every day to ensure that patients are well cared for. It is from this mission of caring for people in times of their greatest vulnerability and need that health-care workers find meaning in their work, as well as their experience of joy.

Yet many health-care workers suffer harm-emotional and physical-in the course of providing care. Many are subjected to being bullied, harassed, demeaned, ignored, and, in the most extreme cases, physically assaulted. They are also physically injured by working in conditions of known and preventable environmental risk. In addition, production and cost pressures have reduced complex, intimate, caregiving relationships into a series of demanding tasks performed under severe time constraints. Under these conditions, it is difficult for caregivers to find purpose and joy in their work or to meet the challenge of making health care safe for patients they serve.

\section{Vulnerable Workplaces}

The basic precondition of a safe workplace is protection of the physical and psychological safety of the workforce. Both are conspicuously absent or considered optional in many care delivery organizations. The prevalence of physical harm experienced by the health-care 
workforce is striking, much higher than in other industries. Up to a third of nurses experience back or musculoskeletal injuries in a year, and many have unprotected contact with blood-borne pathogens.

Psychological harm is also common. In many health-care organizations, staff are not treated with respect-or, worse yet, they are routinely treated with disrespect. Emotional abuse, bullying, and even threats of physical assault and learning by humiliation are all often accepted as "normal" conditions of the health-care workplace, creating a culture of fear and intimidation that saps joy and meaning from work.

The absence of cultural norms that create the preconditions of psychological and physical safety obscures meaning of work and drains motivation. The costs of burnout, litigation, lost work hours, employee turnover, and the inability to attract newcomers to caring professions are wasteful and add to the burden of illness. Disrespectful treatment of workers increases the risk of patient injury.

\section{What Can Be Done?}

An environment of mutual respect is critical if the workforce is to find joy and meaning in work. In modern health care, teamwork is essential for safe practice, and teamwork is impossible in the absence of mutual respect.

Former CEO of Alcoa Paul O'Neill advises that, to find joy and meaning in their daily work, each person in the workforce must be able to answer affirmatively three questions each day:

1. Am I treated with dignity and respect by everyone?

2. Do I have what I need so I can make a contribution that gives meaning to my life?

3. Am I recognized and thanked for what I do?

\section{Developing Effective Organizations}

To create a safe and supportive work environment, health-care organizations must become effective, high-reliability organizations, characterized by continuous learning, improvement, teamwork, and transparency. Effective organizations care for their employees and continuously meet preconditions not subject to annual priority and budget setting. The most fundamental precondition is workforce 
safety, physical and psychological. The workforce needs to know that their safety is an enduring and non-negotiable priority for the governing board, CEO, and organization.

Knowing that their well-being is a priority enables the workforce to be meaningfully engaged in their work, to be more satisfied, less likely to experience burnout, and to deliver more effective and safer care.

Achieving this vision requires leadership. The governing board, CEO, and organizational leaders create the cultural norms and conditions that produce workforce safety, meaning, and joy. Effective leaders shape safety culture through management practices that demonstrate a priority to safety and compassionately engage the workforce to speak about and report errors, mistakes, and hazards that threaten safety - their own or their patients'. Joy and meaning will be created when the workforce feels valued, safe from harm, and part of the solutions for change.

\section{Summary of Recommendations (Table 22.3)}

Table 22.3 Key recommendations from Through the Eyes of the Workforce: Creating Joy, Meaning, and Safer Health Care

\begin{tabular}{l|l}
$\begin{array}{l}\text { Target of } \\
\text { recommendation }\end{array}$ & Recommendation \\
\hline $\begin{array}{l}\text { Hospital and health- } \\
\text { care leaders, } \\
\text { professionals, board } \\
\text { members }\end{array}$ & $\begin{array}{l}\text { Develop and embody shared core values of mutual } \\
\text { respect and civility; transparency and truth telling; } \\
\text { safety of all workers and patients; and alignment and } \\
\text { accountability from the boardroom through the front } \\
\text { lines }\end{array}$ \\
\hline $\begin{array}{l}\text { Hospital and health- } \\
\text { care leaders, } \\
\text { professionals, board } \\
\text { members }\end{array}$ & $\begin{array}{l}\text { Adopt the explicit aim to eliminate harm to workforce } \\
\text { and patients } \\
\text { Recognize and celebrate the work and } \\
\text { accomplishments of the work force, regularly and } \\
\text { with high visibility }\end{array}$ \\
\hline $\begin{array}{l}\text { Hospital and health- } \\
\text { care leaders, board } \\
\text { members, managers }\end{array}$ & $\begin{array}{l}\text { Commit to creating a high-reliability organization } \\
\text { (HRO) and demonstrate the discipline to achieve } \\
\text { highly reliable performance This will require creating } \\
\text { a learning and improvement system and adopting } \\
\text { evidence-based management skills for reliability }\end{array}$ \\
\hline $\begin{array}{l}\text { Hospital and health- } \\
\text { care leaders }\end{array}$ & $\begin{array}{l}\text { Establish data capture, database, and performance } \\
\text { metrics for improvement and accountability }\end{array}$ \\
\hline $\begin{array}{l}\text { Government and } \\
\text { nonprofit funders }\end{array}$ & $\begin{array}{l}\text { Support industry-wide research to explore issues and } \\
\text { conditions in health care that are harming our } \\
\text { workforce and patients }\end{array}$ \\
\hline
\end{tabular}




\section{Progress}

Multiple initiatives are underway to increase awareness of the importance of joy and meaning in work and workforce safety. The National Academy of Medicine and several health-care professional groups and insurers, such as the American Association of Critical-Care Nurses (AACN), the American Nurses Association (ANA Enterprise), the American Medical Association (AMA), and the Harvard Risk Management Foundation are addressing the issue of resilience and burnout.

IHI has developed a framework for increasing joy in work that recommends domains such as reward and recognition, choice and autonomy, camaraderie and teamwork, and physical and psychological safety. Some have observed that the widely accepted Triple Aim should be expanded to include workforce safety and joy and meaning in work - the Quadruple Aim.

Regarding health-care workforce physical safety, noteworthy efforts are proceeding. With the support of the Centers for Medicare \& Medicaid Services (CMS), the US Occupational Safety and Health Administration recently launched an initiative to encourage hospitals and health-care facilities to implement safety and health management systems to prevent injuries among their workforce and patients. Similarly, the Joint Commission has provided detailed reports and tools for improving workforce safety and reducing workplace violence.

\section{Remaining Challenges}

Despite these efforts, according to one recent study, more than half of US physicians suffer from burnout. Among critical-care nurses, $25 \%-33 \%$ have symptoms of severe burnout syndrome. Not only do physicians have higher rates of burnout than the general public, but they also suffer higher rates of depression and suicide. The Covid pandemic has substantially increased all of these problems. The effects of psychological, emotional, and physical harm to the workforce surface in the form of litigation, lost work hours, employee turnover, and inability to attract newcomers to caring professions. With health-care reform, pay-for-performance, the introduction of 
electronic health records, and other innovations, health-care workers spend less time directly caring for patients—-further draining energy, meaning, and joy.

Compounding the issue, a recent survey found that only $23 \%$ of hospital boards review workplace safety dashboards. Our health-care workforce is endangered, and without a healthy, engaged, and supported workforce, safer patient care will remain elusive.

\section{Safety Is Personal [7]}

\section{Partnering with Patients and Families for the Safest Care}

\section{Workshop Leaders: Susan Edgman-Levitan and James Conway}

Receiving safe care is definitely a personal experience. The harm to patients resulting from medical errors at the most vulnerable moments of their lives is a profoundly intimate experience for everyone involved. Clinicians and staff are also deeply affected when they are involved in an adverse event and frequently suffer shame, guilt, fear, and long-lasting depression.

But ensuring safety can also be shared and rewarding. The insights and perspectives of both those who experience care at its best and those who experience it at its worst can help health-care leaders, clinicians, and staff at every level make the improvements needed to create a safer and more patient-centered system.

Engaging patients and families in improving health-care safety means creating effective partnerships between those who provide care and those who receive it - at every level, including individual clinical encounters, safety committees, executive suites, boardrooms, research teams, and national policy-setting bodies. Increasing engagement through effective partnerships can yield many benefits, both in the form of improved health and outcomes for individuals and in safer and more productive work environments for health-care professionals. 
Patients, families, and their advocates increasingly understand the wisdom of this partnership. Too often, standing in the way is the health-care system itself-whether by intention or not-because of its fragmentation, paternalistic professional culture, abundance of poor process design, and lack of experience on the part of health-care leaders and clinicians with practical methods of engaging patients in the safety enterprise.

While patients and families can play a critical role in preventing medical errors and reducing harm, the responsibility for safe care lies primarily with the leaders of health-care organizations and the clinicians and staff who deliver care. Many of the barriers to engagement faced by patients and families - such as lack of access to their health records, intimidation, fear of retribution, and lack of easy-to-understand tools and checklists for enhancing safe care-can only be overcome if leaders and clinicians support patients and families to become more confident and effective in their interactions with health-care providers. Many of the tools necessary to do this already exist, but the system must also provide the education and training needed by professionals and patients alike to become more effective partners.

Summary of Recommendations (Table 22.4)

\section{Progress}

With the increasing use of decision aids, patient portals, OpenNotes, care engagement plans, and the spread of Patient and Family Advisory Councils (PFACs), health-care leaders and clinicians are beginning to understand the power of engaging patients and families as integral partners. The OpenNotes program has demonstrated that patients can contribute to preventing or mitigating errors.

Patient experience data is being used more widely and effectively. Mandates from CMS, the National Committee for Quality Assurance (NCQA), and other payers for use and improvement of Consumer Assessment of Healthcare Providers and Systems (CAHPS) patient experience survey data are linked to improved performance and outcomes.

Health-care systems, hospitals, and ambulatory practices are also beginning to incorporate patient preferences into care design by 
Table 22.4 Key recommendations from Safety Is Personal: Partnering with Patients and Families for the Safest Care

\begin{tabular}{l|l}
$\begin{array}{l}\text { Target of } \\
\text { recommendation }\end{array}$ & Recommendation \\
\hline $\begin{array}{l}\text { Leaders of health } \\
\text { systems }\end{array}$ & $\begin{array}{l}\text { Establish patient and family engagement as a core value } \\
\text { by involving patients and families as equal partners in all } \\
\text { organizational activities. Educate and train clinicians and } \\
\text { staff to be effective partners; and partner with patient } \\
\text { advocacy groups and community organizations to increase } \\
\text { public awareness and engagement }\end{array}$ \\
\hline $\begin{array}{l}\text { Health-care } \\
\text { clinicians and } \\
\text { staff }\end{array}$ & $\begin{array}{l}\text { Support patients and families to engage effectively in their } \\
\text { own care by providing the information, training, and tools } \\
\text { they need to manage their health conditions according to } \\
\text { their expressed wishes } \\
\text { Engage patients as equal partners in safety improvements } \\
\text { and care design } \\
\text { Support patients and families when things go wrong }\end{array}$ \\
\hline $\begin{array}{l}\text { Health-care policy } \\
\text { makers }\end{array}$ & $\begin{array}{l}\text { Involve patients in all policy-making committees and } \\
\text { programs } \\
\text { Develop, implement, and report safety metrics that foster } \\
\text { accountability and transparency } \\
\text { Engage patients in setting and implementing the research } \\
\text { agenda }\end{array}$ \\
\hline $\begin{array}{l}\text { Patients and } \\
\text { families and the } \\
\text { public }\end{array}$ & $\begin{array}{l}\text { medicines and care plans. They should also be instructed } \\
\text { in basic safety steps: repeating back instructions and } \\
\text { information to clinicians in their own words; bringing a } \\
\text { friend or family member to all appointments; and } \\
\text { understanding who is in charge of their care }\end{array}$ \\
\hline
\end{tabular}

including patients and their families as active participants in codesign and research studies funded by the Patient-Centered Outcomes Research Institute (PCORI). The internationally observed "What Matters to You?" Day aims to encourage meaningful conversations between patients, families, and providers.

Patient and family perspectives are valuable in many arenas, from design of the physical environment and care coordination plans to reporting safety concerns and participation in root cause analyses. Patient engagement should be authentic and take place across the continuum of care from the bedside to the boardroom to national policy committees. The newly established Patient Experience Policy Forum 
affiliated with the Beryl Institute is advocating for patient and family partnerships in codesign and policy making nationally.

\section{Remaining Challenges}

While some exemplary organizations are fully engaging patients in the care process, ample opportunities for improvement remain. Many organizations lack effective PFACs and have not devoted resources to train staff in shared decision-making practices or to offer evidencebased decision aids. The current fee-for-service payment system does not encourage clinicians to spend the time needed to communicate with patients nor to elicit their preferences.

Many organizations still lack process improvement skills to support integrating better communication into clinical workflows. As care shifts from inpatient to ambulatory and home care settings, patients and families are becoming more responsible for delivering their own care. However, they may not be well equipped to manage complicated medication regimens, activities of daily living, medical devices, or infection control procedures.

Overwhelming evidence indicates that collecting patient feedback and including patients as equal partners in their care support improvement in both patient experience of care and clinical outcomes. Opportunities remain to partner with patients, families, and communities to accelerate improvement in education, patient satisfaction, and quality of care.

\section{Shining a Light [8]}

\section{Safer Health Care Through Transparency}

\section{Workshop Leaders: Gary Kaplan and Robert Wachter}

During the course of health care's patient safety and quality movements, the impact of transparency-the free, uninhibited flow of information that is open to the scrutiny of others-has been far more positive than many had anticipated, and the harms of transparency have been far fewer than many had feared. Yet important obstacles to 
transparency remain, ranging from concerns that individuals and organizations will be treated unfairly after being transparent to more practical matters related to identifying appropriate measures on which to be transparent and creating an infrastructure for reporting and disseminating the lessons learned from others' data.

To address the issue of transparency in the context of patient safety, the National Patient Safety Foundation's Lucian Leape Institute held two roundtable discussions involving a wide variety of stakeholders representing myriad perspectives. In the discussions and in this report, the choice was made to focus on four domains of transparency:

- Transparency between clinicians and patients (illustrated by disclosure after medical errors)

- Transparency among clinicians themselves (illustrated by peer review and other mechanisms to share information within healthcare delivery organizations)

- Transparency of health-care organizations with one another (illustrated by regional or national collaboratives)

- Transparency of both clinicians and organizations with the public (illustrated by public reporting of quality and safety data)

One key insight was the degree to which these four domains are interrelated. For example, creating environments in which clinicians are open and honest with each other about their errors within organizations (which can lead to important system changes to prevent future errors) can be thwarted if these clinicians believe they will be treated unfairly should the same errors be publicly disclosed. These tensions cannot be wished away; instead, they must be forthrightly addressed by institutional and policy leaders.

In this report, the NPSF Lucian Leape Institute comes down strongly on the side of transparency in all four domains. The consensus of the roundtable discussants and the Institute is that the evidence supports the premise that greater transparency throughout the system is not only ethically correct but will lead to improved outcomes, fewer errors, more satisfied patients, and lower costs. The mechanisms for these improvements are several and include the ability of transparency to support accountability, stimulate improvements in quality and safety, promote trust and ethical behavior, and facilitate patient choice. 
In the report, more than three dozen specific recommendations are offered to individual clinicians, leaders of health-care delivery organizations (e.g., CEOs, board members), and policy makers.

If transparency were a medication, it would be a blockbuster, with billions of dollars in sales and accolades the world over. While it is crucial to be mindful of the obstacles to transparency and the tensions - and the fact that many stakeholders benefit from our current largely nontransparent system-our review convinces us that a healthcare system that embraces transparency across the four domains will be one that produces safer care, better outcomes, and more trust among all of the involved parties. Notwithstanding the potential rewards, making this happen will depend on powerful, courageous leadership and an underlying culture of safety.

Summary of Recommendations (Table 22.5)

\section{Progress}

Today, the call for greater transparency in health care is growing louder. Consumers have begun to post reviews of their physicians, care teams, and health-care organizations on online review platforms. Moreover, some health-care systems are now collecting and posting information from patient experience surveys at the service or physician level. Recently, several health systems have begun to provide forums for free-response comments online, often with positive results.

The 2005 Patient Safety and Quality Improvement Act and the rise of patient safety organizations (PSOs) have facilitated increased transparency among clinicians and health-care organizations. Additionally, collaboratives like Solutions for Patient Safety (SPS), a network of more than 130 children's hospitals working together to eliminate serious harm, have shown compelling evidence that sharing data, successes, and failures can markedly accelerate learning and improvement.

Health care is also seeing greater transparency between patients and clinicians in the aftermath of adverse events. A growing number of communication and resolution programs have been established, fueled by growing evidence that prompt disclosure, honesty, and 
Table 22.5 Key recommendations from Shining a Light: Safer Health Care Through Transparency

\begin{tabular}{|c|c|}
\hline $\begin{array}{l}\text { Target of } \\
\text { recommendation }\end{array}$ & Recommendation \\
\hline All stakeholders & $\begin{array}{l}\text { Ensure disclosure of conflicts of interest, and provide } \\
\text { patients with reliable information in a form that is } \\
\text { useful to them } \\
\text { Create organizational cultures that support } \\
\text { transparency, shared learning, and core competencies } \\
\text { regarding communication with patients and families, } \\
\text { other clinicians, and the public }\end{array}$ \\
\hline Leaders and boards & $\begin{array}{l}\text { Prioritize transparency and safety, and frequently } \\
\text { review comprehensive safety performance data } \\
\text { Link hiring, firing, promotion, and compensation to } \\
\text { results in cultural transformation and transparency }\end{array}$ \\
\hline $\begin{array}{l}\text { Governmental } \\
\text { agencies }\end{array}$ & $\begin{array}{l}\text { Develop data sources for collection of safety data, } \\
\text { improve standards and training materials for core } \\
\text { competencies, and develop an all-payer database and } \\
\text { robust medical device registries }\end{array}$ \\
\hline Clinicians & $\begin{array}{l}\text { Inform patients of clinician's experience, conflicts of } \\
\text { interest, and role in care, and provide patients with a } \\
\text { full description of all the alternatives for tests and } \\
\text { treatments and the pros and cons for each } \\
\text { Provide patients with full information about all } \\
\text { planned tests and treatments }\end{array}$ \\
\hline $\begin{array}{l}\text { Hospitals and health } \\
\text { systems }\end{array}$ & $\begin{array}{l}\text { Provide patients with full access to their medical } \\
\text { records, and include patients and family members in } \\
\text { interdisciplinary bedside rounds }\end{array}$ \\
\hline $\begin{array}{l}\text { Hospitals and health } \\
\text { systems, health } \\
\text { professionals }\end{array}$ & $\begin{array}{l}\text { Provide patients and families with full information } \\
\text { about any harm resulting from treatment, followed by } \\
\text { apology and fair resolution } \\
\text { Provide patients and clinicians support when they are } \\
\text { involved in an incident. Include patients/family } \\
\text { members in event reporting and in root cause analysis }\end{array}$ \\
\hline $\begin{array}{l}\text { Hospital and health } \\
\text { leaders }\end{array}$ & $\begin{array}{l}\text { Create a safe, supportive culture for caregivers to be } \\
\text { transparent and accountable to each other } \\
\text { Create multidisciplinary processes and forms for } \\
\text { reporting, analyzing, and sharing data } \\
\text { Create processes to hold individuals accountable for } \\
\text { risky or disruptive behavior }\end{array}$ \\
\hline $\begin{array}{l}\text { Health-care } \\
\text { organizations, hospital } \\
\text { associations, PSOs }\end{array}$ & $\begin{array}{l}\text { Have clear mechanisms for sharing and adopting best } \\
\text { practices, for example, by participating in state and } \\
\text { regional collaboratives }\end{array}$ \\
\hline $\begin{array}{l}\text { Hospitals and health- } \\
\text { care organizations }\end{array}$ & $\begin{array}{l}\text { Report and publicly display measures used to monitor } \\
\text { quality and safety, and clearly communicate to the } \\
\text { public about performance }\end{array}$ \\
\hline
\end{tabular}


apology following patient injury can decrease medical malpractice liability and improve the satisfaction of all parties. Toolkits are now available to promote such programs.

\section{Remaining Challenges}

Many challenges to achieving full transparency remain. A recent survey found that less than $40 \%$ of quality and safety leaders rated their board's understanding of disclosure and apology as "high," and even fewer felt their boards had a comprehensive understanding of safety concepts related to transparency about error and harm. Transparency within organizations and between providers requires creating an environment of trust as well as improving technology and processes to ensure they are efficient and effective and promote regular open and honest communication and data sharing.

Transparency with the public is equally challenging. Hospital and clinician concerns about litigation; reputational costs; and the accuracy, interpretability, and comprehensiveness of safety metrics need to be addressed. Additionally, national rating systems and websites, including Leapfrog and U.S. News \& World Report, share few common scores and often generate more confusion than clarity. For example, as of 2015 no hospital was rated as a high performer by all four major national US rating systems. In the future, data must be understandable and actionable for both patients and provider organizations.

As more organizations publicly share their quality, safety, and patient experience data, transparency will be increasingly demanded by all stakeholders. To benefit patients as well as care providers, organizations will need to prepare their boards, clinicians, and staff for a more transparent health-care system. Transparency at these levels will eventually facilitate decision-making about where to receive care and where to work, but a long road lies ahead to make this comparable and uniform across all health entities.

The last of the five white papers was published in 2015. Printed copies of all of them were circulated widely to CEOs and patient safety leaders of schools and health-care organizations, patient safety specialists, and members of the roundtables, who you will recall 
included individuals and leaders of organizations that could implement the recommendations.

While all of the reports were well-received, it is impossible to know their impact. Implementing the recommendations requires strong leadership and major cultural changes. Stimulating those changes, of course, is what we were trying to do with the white papers by providing the evidence, the arguments, and the tools for change. Some minds were undoubtedly changed. The foundation was laid for the transformations needed to make health care safe.

\section{Transforming Health Care: A Compendium}

While the white papers got good reviews and wide circulation, we were well aware that their lengths would be barriers to reading them for many who would benefit from them. So, when the last of the five white papers was finished in 2015, we wrote a compendium that brought together the executive summary and recommendations for each of the five topics, plus additional recommendations for getting started on making the changes: Transforming Health Care: A Compendium of Reports from the National Patient Safety Foundation's Lucian Leape Institute [2].

Our hope was that this 30-page document would not only make some of the many lessons and critical insights we had gathered more accessible, but that it would also stimulate readers to read the original monographs. Like the white papers, Transforming Health Care: A Compendium is available free on the IHI website.

\section{Members}

Since its inception, the membership of the Institute has changed as new members were added and others retired. Early on, we invited patient advocate Susan Edgman-Levitan, Executive Director of the John D. Stoeckle Center for Primary Care Innovation at the MGH to join us. To bring in outside perspectives, we were fortunate to attract Paul O'Neill, former CEO of Alcoa and 72nd United States Secretary of the Treasury, and James Guest, head of Consumers Union. Janet Corrigan, former IOM staff director for To Err is Human joined us 
shortly thereafter, as did Robert M. Wachter, founder of the hospitalist specialty and Associate Chair Department of Medicine, UCSF, and Charles Vincent, UK leader of patient safety research of the University of Oxford.

Later additions included Amy Edmondson, Professor at Harvard Business School; Sue Sheridan, Director of Patient Engagement, Patient-Centered Outcomes Research Institute; David Michaels, former Head of the Occupational Safety and Health Administration; Gregg Meyer, Chief Clinical Officer Of Mass General Brigham; and Joanne Disch, former Chair of the Board of Advocate-Aurora Health System.

In 2014, Tejal Gandhi became president of the Institute when Diane Pinakiewicz retired. Gary Kaplan, CEO of Virginia Mason Medical Center, joined LLI when he stepped down as chair of the Board of NPSF. He took over as chair of the Institute when I retired in 2015.

In addition to the five white papers, LLI pursued a number of other strategic efforts to motivate change for patient safety. From the beginning, the annual fund-raising gala had a major educational component. Prior to the evening social event, we presented a full afternoon symposium that provided a variety of unique learning opportunities for attendees, such as an open forum where they could hear presentations and question LLI members and breakout sessions on specific patient safety topics. The evening program featured an address by a world-renowned safety expert.
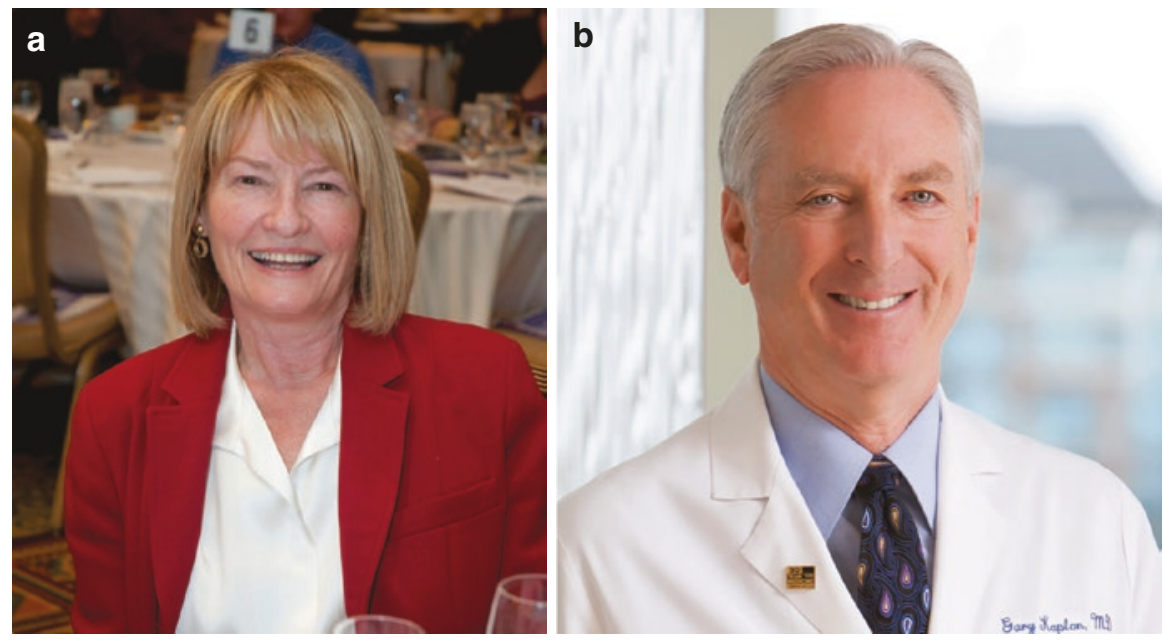

(a) Susan Edgman-Levitan and (b) Gary Kaplan. (All rights reserved) 
The Institute held a fund-raising gala each year, which included an afternoon educational program conducted by the members and an evening banquet with a featured celebrity speaker. These were highly successful events attracting several hundred attendees each year.

LLI members also participated as faculty in the leadership course and other activities at the annual NPSF Congress. A highly popular feature was the annual LLI panel where several members discussed a current patient safety topic.

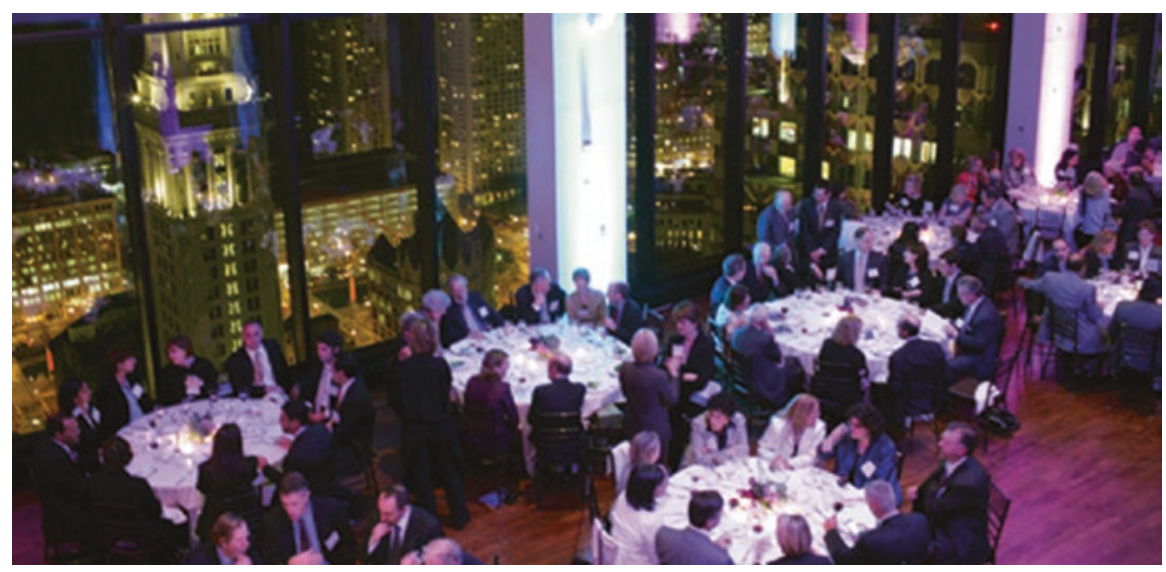

LLI Gala. Source: National Patient Safety Foundation (now Institute for Healthcare Improvement). (All rights reserved)

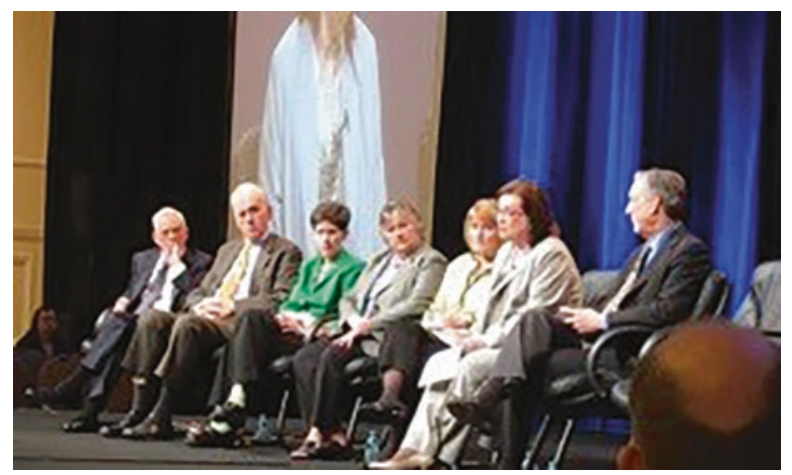

LLI Panel. From left to right: Paul O’Neill, Jim Conway, Carolyn Clancy, Pam Thompson, Susan EdgmanLevitan, Julie Morath, Gary Kaplan. (Source: National Patient Safety Foundation (now Institute for Healthcare Improvement). All rights reserved) 


\section{Later Work}

\section{The "Must Do" List}

As the concept of responding to errors by treating them as systems problems instead of blaming individuals became widely accepted, some applied the idea to all failures, and the term "no-blame" culture emerged. This misconception was countered by the definition and promotion of the "Just Culture" as defined by Reason and David Marx, who distinguished error from negligence, reckless behavior, and intentional rule violations $[9,10]$.

Rule violations can be tricky, since there are times when a nonstandard response is required in an individual situation. These should be dealt with on an individual basis. But most violations are not in that category; they result from individual preferences, inconvenience, or resistance to change. A fair and just culture demands that such individual violators be held accountable. Unfortunately, health-care organizations varied widely in which practices they placed in this category and how they responded to violations. Few consistently enforced meaningful sanctions.

Members of LLI were of a single mind that certain safe practices were of such undisputed value that they should be universally followed and that sanctions should be applied to violators, i.e., some failures are truly "blameworthy." The practices in this category are those that (1) are effective at preventing an important harm, (2) have substantial impact, (3) are feasible to comply with and audit, and (4) have been accepted as a standard by the NQF and professional consensus. These are safety practices that have sufficiently compelling supportive evidence that clinicians should not have the right of an individual veto. We called them "Must Do" practices.

These concepts were laid out by Bob Wachter in a paper on the Health Affairs Blog, The 'Must Do' List: Certain Patient Safety Rules Should Not Be Elective, that provided the rationale for this approach. It identified two practices that currently met the criteria: hand hygiene and influenza vaccination for health-care workers [11].

We called on health-care organizations to expect 100 percent adherence to these practices, to sanction violators, and to be willing to terminate clinicians for deliberate and repeated noncompliance with either of these practices. We recommended that expectation of 
universal compliance with required practices be included in bylaws and clinician compacts. We also called on the Joint Commission and CMS and other regulators and accreditors to adopt these standards.

\section{Financial Costs of Patient Safety}

One of the arguments given by health-care organizations for not moving ahead more aggressively to improve patient safety was that they could not afford it, that implementing new practices costs more than they save. As measurement of adverse events began to take hold, however, research showed that the costs of the additional care and prolonged hospital stays caused by preventable injuries are substantial. The additional cost has been estimated at \$16-18 billion annually [12] but is probably considerably higher because of underreporting. The cost of hospital-acquired infections alone has been estimated as more than $\$ 10$ billion a year [13].

Hospitals were able to absorb these costs because they could bill for additional days and services caused by the injury. That began to change during the Obama Administration with the move toward value-based purchasing. Under bundled and capitated payment programs, the marginal costs of treating injuries are not compensated, eroding hospital margins. Suddenly reducing those harms became more attractive.

LLI decided to write a paper to encourage purchasers to promote safety through financial incentives and identify what further steps could be taken to strengthen marketplace incentives. In On the safe side: the move to value-based payment models could mean improvements in patient safety, Corrigan et al. pointed the way [14]. In addition to the direct benefit to patients from reducing adverse events, creating a safe environment enhances workplace productivity, morale, and retention. In the competitive marketplace, improved safety enhances the system's reputation and ability to increase market share. Malpractice costs will decline.

We called on executives to increase awareness of the costs by including estimates of the direct and indirect expenses associated with medical errors in financial statements shared with trustees, leadership, staff, and the public and to ensure that a portion of their organizations' capital budgets are allocated for investments in safety such as 
barcoding. When the financial consequences of unsafe care are accounted for, it is clear that investing in patient safety is both the right thing to do and the profitable thing to do.

\section{Collaboration with American College of Healthcare Executives}

As health-care organizations gained experience with changing systems, it became increasingly clear that more extensive culture changes were needed, and this required strong leadership. LLI began to look for strategies to engage and motivate health-care systems leaders.

In 2015, LLI approached the American College of Healthcare Executives (ACHE) regarding a joint effort. The timing was fortuitous. Under new leadership, ACHE was seeking to establish itself as a thought leader in the executive space. We formed a partnership to sponsor two roundtables on leading a culture of safety, co-chaired by leaders of the two organizations.

The participants in these roundtables, held in 2016, included CEOs and patient safety officers from a number of hospitals and systems, large and small, academics, and leaders of professional organizations, such as the AONE, AHA, ANA, and IHI, and leadership consulting organizations.

The work of the roundtables was summarized with recommendations in Leading a Culture of Safety: A Blueprint for Success, published jointly by ACHE and LLI [15]. This is probably the most comprehensive and useful guide for creating a culture of safety. It is described in more detail in the next chapter.

Since 2015, the end of the period of this history, NPSF merged with IHI, which committed to continuing support of LLI. Major LLI initiatives since then include:

- Partnering with NORC at the University of Chicago to conduct a survey of American's experience with medical errors and views on patient safety [16].

- Transforming concepts in patient safety: a report on progress in each of the five areas since they were formulated in 2009 [3].

- Framework for Effective Board Governance of Health System Quality [17].

- The Salzburg Statement on Moving Measurement into Action: Global Principles for Measuring Patient Safety [18]. 


\section{Conclusion}

How much impact the white papers and other LLI initiatives have had on making health care safer is impossible to know. The roundtables for the five transforming concepts and the one engaging leaders with ACHE were highly motivating for the participants. These key organizational and policy leaders - the "movers and shakers"-were enthusiastic participants, and the discussions clearly advanced thinking about each of the issues in practical and actionable ways.

The roundtables and white papers also appear to have significantly increased awareness of the complex issues in patient safety and deepened understanding of these issues for many other leaders in health care. They truly changed the conversation and helped put patient safety on everyone's agenda. To that extent, the Institute has made great progress in meeting its charge, to "define strategic paths and calls to action for the field of patient safety."

\section{References}

1. Leape L, Berwick D, Clancy C, et al. Transforming healthcare: a safety imperative. Qual Saf Health Care. 2009;18(6):424-8.

2. National Patient Safety Foundation's Lucian Leape Institute. Transforming health care: a compendium of reports from the NPSF Lucian Leape Institute. Boston: National Patient Safety Foundation; 2016.

3. Gandhi TK, Kaplan GS, Leape L, et al. Transforming concepts in patient safety: a progress report. BMJ Qual Saf. 2018;27(12):1019-26.

4. National Patient Safety Foundation. Unmet needs: teaching physicians to provide safe patient care. Boston; 2010.

5. Lucian Leape Institute. Order from Chaos: accelerating care integration. Boston: National Patient Safety Foundation; 2012.

6. Lucian Leape Institute. Through the eyes of the workforce: creating joy, meaning, and safer health care. Boston: National Patient Safety Foundation; 2013.

7. National Patient Safety Foundation's Lucian Leape Institute. Safety is personal: partnering with patients and families for the safest care. Boston: National Patient Safety Foundation; 2014.

8. National Patient Safety Foundation's Lucian Leape Institute. Shining a light: safer health care through transparency. Boston: National Patient Safety Foundation; 2015.

9. Reason JT. Managing the risks of organizational accidents. Aldershot, Hants; Brookfield: Ashgate; 1997.

10.Marx D. Patient safety and the "just culture": a primer for health care executives. New York. 17 Apr 17, 2001. 
11. Wachter RM. The 'Must Do' list: certain patient safety rules should not be elective. In. Health Affairs Blog. Vol 2020: Health Affairs; 20 Aug 2015.

12.U.S. Department of Health and Human Services. New HHS data shows major strides made in patient safety, leading to improved care and savings. 7 May 2014.

13.Zimlichman E, Henderson D, Tamir O, et al. Health care-associated infections: a meta-analysis of costs and financial impact on the US health care system. JAMA Intern Med. 2013;173(22):2039-46.

14.Corrigan JM, Wakeam E, Gandhi TK, Leape LL. On the safe side: the move to value-based payment models could mean improvements in patient safety. Healthc Financ Manage. 2015;69(8):94.

15. American College of Healthcare Executives and IHI/NPSF Lucian Leape Institute. Leading a culture of safety: a blueprint for success. Boston: American College of Healthcare Executives and Institute for Healthcare Improvement; 2017.

16.NORC at the University of Chicago and IHI/NPSF Lucian Leape Institute. Americans' experiences with medical errors and views on patient safety. Cambridge: Institute for Healthcare Improvement and NORC at the University of Chicago; 2017.

17.Daley Ullem E, Gandhi TK, Mate K, Whittington J, Renton M, Huebner J. Framework for Effective Board Governance of Health System Quality. IHI White Paper. Boston: Institute for Healthcare Improvement; 2018.

18.Salzburg Global Seminar \& Institute for Healthcare Improvement. The Salzburg statement on moving measurement into action: global principles for measuring patient safety: Institute for Healthcare Improvement and Salzburg Global Seminar; 2019.

Open Access This chapter is licensed under the terms of the Creative Commons Attribution 4.0 International License (http://creativecommons.org/ licenses/by/4.0/), which permits use, sharing, adaptation, distribution and reproduction in any medium or format, as long as you give appropriate credit to the original author(s) and the source, provide a link to the Creative Commons license and indicate if changes were made.

The images or other third party material in this chapter are included in the chapter's Creative Commons license, unless indicated otherwise in a credit line to the material. If material is not included in the chapter's Creative Commons license and your intended use is not permitted by statutory regulation or exceeds the permitted use, you will need to obtain permission directly from the copyright holder.

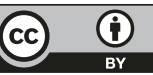

